\title{
Increasing the rate of drying reduces metabolic imbalance, lipid peroxidation and critical water content in radicles of garden pea (Pisum sativum L.)
}

\author{
Tobias M. Ntuli ${ }^{1,2,{ }^{*},}$ Norman W. Pammenter ${ }^{1}$ and Patricia Berjak ${ }^{1}$ \\ 1 Plant Germplasm Conservation Research, School of Life Sciences, University of KwaZulu-Natal, Private Bag X54001, Durban 4000, South Africa. \\ 2 Department of Life and Consumer Sciences, University of South Africa, Private Bag X6, Florida 1710, Johannesburg, South Africa.
}

\begin{abstract}
Orthodox seeds become desiccation-sensitive as they undergo germination. As a result, germinating seeds serve as a model to study desiccation sensitivity in plant tissues. The effects of the rate of drying on the viability, respiratory metabolism and free radical processes were thus studied during dehydration and wet storage of radicles of Pisum sativum. For both drying regimes desiccation could be described by exponential and inverse modified functions. Viability, as assessed by germination capacity and tetrazolium staining, remained at $100 \%$ during rapid $\left(<24 \mathrm{~h}\right.$ ) desiccation. However, it declined sharply at c. $0.26 \mathrm{~g} \mathrm{~g}^{-1} \mathrm{dm}$ following slow (c. 5 days) drying. Increasing the rate of dehydration thus lowered the critical water content for survival. Rapid desiccation was also associated with higher activities and levels of malate dehydrogenase and the oxidized form of nicotinamide adenine dinucleotide. It was also accompanied by lower hydroperoxide levels and membrane damage. In addition, the activitiy of glutathione reductase was greater during rapid drying. Ageing may have contributed to increased damage during slow dehydration, since viability declined even in wet storage after two weeks. The results presented are consistent with rapid desiccation reducing the accumulation of damage resulting from desiccation-induced aqueous-based deleterious reactions. In addition, they show that radicles are a useful model to study desiccation sensitivity in plant tissues.
\end{abstract}

Keywords: Antioxidant, desiccation, drying rate, free radical processes, lipid peroxidation, metabolism, respiration, Pisum sativum, seed storage.

Abbreviations: AsA, ascorbic acid; CAT, catalase; GR, glutathione reductase; $\mathrm{MDH}$, malate dehydrogenase; NAD, nicotinamide adenine dinucleotide; PFK, phosphofructokinase; SOD, superoxide dismutase; TZ, tetrazolium.

\section{INTRODUCTION}

Recalcitrant seeds and vegetative tissues are desiccationsensitive (reviewed by Berjak, 2006). As a result, recalcitrant seeds are unstorable by conventional methods for orthodox seeds (reviewed by Berjak and Pammenter, 1997a, b; 2001; 2004 ; 2008). In addition, they may not be produced in particular seasons. Thus conservation of their genetic resources and accessibility for study is presently limited. Radicles become desiccation-sensitive as they undergo germination. Consequently, they provide an always-accessible model to study desiccation-sensitivity in seeds. In addition, they eliminate the introduction of extraneous factors by vegetative tissues.

In addition to physical stresses that desiccation-sensitive seed tissues incur as a consequence of dehydration, they are subject to metabolic damage. It has been argued that desiccation differentially affects the activities of various enzymes (Farrant et al., 1985; Leprince et al., 1993a; 1994; 1995; 1999; 2000; reviewed by Côme and Corbineau, 1996; Leprince and Hoekstra, 1998; Ntuli et al., 2011) and hence results in metabolic imbalance (Finch-Savage et al., 1993; reviewed by Vertucci and Farrant, 1995; Leprince et al., 2000; Walters et al., 2002; Ntuli et al., 2011). Of particular interest in this regard is respiratory metabolism. For instance, it has been shown that phosphofructokinase (PFK) and malate dehydrogenase (MDH) were slightly and mildly affected by dehydration, respectively, while the glucose-6-phosphate dehydrogenase (G6PDH) and $\mathrm{NADH}$ dehydrogenase of the NADH-ubiquinone (coenzyme Q) reductase (complex I) were extremely sensitive to desiccation in germinating maize (Leprince et al., 1992; 1993a; 1994). In contrast, Carpenter et al. (1987) observed that PFK was highly sensitive to in vitro desiccation. In this regard, it is noteworthy that the cause of the differences in sensitivity among enzymes is unknown. More recently, Song et al. (2009) reported a decline in the activity of malate dehydrogenase in recalcitrant Antiaris toxicaria radicles and orthodox Zea mays embryos during dehydration.

It has been suggested that desiccation-induced disruption of the electron transport chain of mitochondrial and microsomal membranes between the ubiquinone pool and cytochrome oxidase may result in more leakage of electrons from the electron transport chain than normal, thus generating the accumulation of free radical species which are associated with lipid peroxidation (Leprince et al., 1990; 1994; 1995; Hendry et al., 1992; Hendry, 1993). More recently, Song et al. (2009) reported a decline in the activity of cytochrome c oxidase in recalcitrant Antiaris toxicaria radicles and orthodox Zea mays embryos during dehydration.

However, it remains unclear whether oxidative damage is a cause or consequence of tissue damage and/or death (Hendry et al., 1992; reviewed by Leprince and Golovina, 2002). Roach et 
al. (2010) demonstrated extracellular superoxide production in response to desiccation in recalcitrant Castanea sativa seeds.

A number of processes associated with seed desiccation tolerance have been identified. They include, inter alia, accumulation of soluble sugars, the synthesis of late embryogenesis abundant (LEA) proteins and the nature and efficiency of free radical processing systems (reviewed by Crowe et al., 1992; Leprince et al., 1993b; Horbowicz and Obendorf, 1994; Vertucci and Farrant, 1995; Close, 1996; Berjak and Pammenter, 1997a; b; 2001; 2004; 2008; Pammenter and Berjak, 1999; Buitink et al., 2002; Berjak, 2006). For instance, Hendry et al. (1992) demonstrated that dehydration of desiccation-sensitive embryonic radicles of Quercus robur resulted in decreases in the activities of superoxide dismutase (SOD), glutathione reductase (GR), ascorbate peroxidase (APOD) and the level of $\alpha$-tocopherol. In contrast, there was an increase in the level of ascorbate (AsA) during dehydration. However, guaicol peroxidase (GPOD) was not affected by drying. No catalase (CAT) activity was detected. More recently, Song and co-workers have shown a decline in activities of SOD, APOD, CAT, GR, and dehydroscorbate reductase (DHAR) and SOD, APO and CAT in radicles of Trichilia dregeana and Chinese wampee during dehydration (Song et al., 2005; Huang et al., 2009, respectively).

Several studies have shown that rapid drying of desiccation-sensitive seeds permits survival to lower water content than slow drying (Berjak et al., 1984; Farrant et al., 1985; 1989; Grabe, 1989; Pritchard, 1991; Pammenter et al., 1991; 1998; 1999; Walters et al., 2001; Wesley-Smith et al., 2001; Huang et al., 2009; Ntuli et al., 2011). It has been proposed that such behavior depends upon rapid drying removing water sufficiently fast to reduce the accumulation of damage resulting from aqueous-based deleterious reactions (Berjak et al., 1989; 1993; Pammenter et al., 1991; 1998; 1999; Pritchard, 1991).

Wet storage may be equated to long-term low-intensity desiccation (e. g. Pammenter et al., 1994). It is not surprising that the deleterious reactions involved during hydrated storage such as metabolic imbalance, lipid peroxidation and disruption of antioxidant systems are similar (e. g. Ntuli et al., 2011).

In the present study, the effects of the rate of drying on viability, respiratory metabolism and free radical processes were monitored during dehydration and wet storage of radicles of Pisum sativum.

\section{MATERIALS AND METHODS}

\section{Plant material}

Seeds of garden pea (Pisum sativum L. var Greenfeast) were bought from Pannar, Greytown, South Africa. They were allowed to imbibe water for $6 \mathrm{~h}$, surface sterilised and set out to germinate in germination trays on moist paper towel at room temperature under constant light for $72 \mathrm{~h}$.

Radicles were excised from cotyledons and accumulated on moist filter paper in closed Petri dishes. Only radicles longer than $10 \mathrm{~mm}$ were used for subsequent experiments.

\section{Treatments}

Radicles were partitioned into three samples. Each sample was aseptically placed in sterile containers over: (1) activated silica gel with a fan mounted (rapid drying [close to $0 \% \mathrm{RH}$ ), or
(2) a saturated solution of sodium chloride (slow dehydration [75 $\pm 1 \% \mathrm{RH}]$ ) or distilled water (wet storage [100\% RH]). The containers were stored at $15 \pm 1{ }^{\circ} \mathrm{C}$.

\section{Water content determinations}

Water contents were determined gravimetrically after drying radicles in the oven at $80{ }^{\circ} \mathrm{C}$ for 48 hours. Masses were determined periodically during dehydration and wet storage. The water contents are reported as means \pm SE for five individual radicles, expressed on a dry mass basis $\left(\mathrm{g} \mathrm{g}^{-1}\right)$.

Assessment of drying rates

Drying rates were assessed either as the rate constant $(\beta)$ of an exponential decline in water content (Liang and Sun, 2000; Sun, 2002), calculated as slopes of log-transformed water contents against time, or as the constant $(b)$ of the modified inverse function relating relative water content (RWC) to time (RWC $=b /(b+t)$, where RWC is the water content relative to the initial water content, and $\mathrm{t}$ is drying time (Pammenter et al., $2002 ; 2003), b$ being calculated as the slope of a plot of $1 /$ RWC against time.

\section{Viabillity tests}

To minimize the effects of imbibing damage, dehydrated radicles were moistened on damp filter paper in Petri dishes overnight at $20{ }^{\circ} \mathrm{C}$ before being subjected to the tetrazolium and conductivity tests.

To assess germination capacity, radicles were cultured in Petri dishes on half MS medium (Musharige and Skoog, 1962) supplemented with $0.3 \mathrm{~g} \mathrm{l}^{-1}$ sucrose, photoperiod $16 \mathrm{~h}$, under sterile conditions for a period of 20 days at room temperature. Radicles were scored as germinated when they showed greening and/or elongation and/or expansion.

Apparent radicles viability was determined by the tetrazolium test. Twenty moistened radicles were cut through longitudinally, soaked in $1 \%(\mathrm{w} / \mathrm{v})$ 2,3,5-triphenyltetrazolium chloride solution for $24 \mathrm{~h}$ in the dark at $20^{\circ} \mathrm{C}$, and scored using intensity and location of staining as criteria (International Seed Testing Association, 1996).

Electrolyte leakage from five replicates of individual moistened radicles was measured using a multi-cell conductivity meter (CM100; Reid and Associates cc, Durban, SA) over $12 \mathrm{~h}$. All measurements were made at $2 \mathrm{~V}$ whilst radicles were immersed in $1 \mathrm{ml}$ of distilled water. Leakage was recorded as the highest reading over the measurement period. The results are reported as means \pm SE of the five replicate radicles.

\section{Assays of respiratory enzymes}

Phosphofructokinase (PFK) activity was determined according to Leprince et al. (1993a). Radicles (c. $5 \mathrm{mg}$ dry matter) were homogenized to a fine powder under liquid nitrogen using a pestle and mortar. Soluble proteins were extracted from the frozen powder in $5 \mathrm{ml}$ of $50 \mathrm{mM}$ Tris- $\mathrm{HCl}$ ( $\mathrm{pH} \mathrm{7.6)} \mathrm{in}$ the presence of $0.1 \%$ polyvinylpyrolidone (PVP) (Hofmann and Kopperschläger, 1982) and the homogenate centrifuged at $8000 \mathrm{~g}$ for $5 \mathrm{~min}$. An aliquot of $2 \mathrm{ml}$ of the supernatant was then transferred to $1 \mathrm{ml}$ of a mixture of $0.2 \mathrm{mM}$ 
ethylenediaminetetraacetic acid (EDTA), $2 \mathrm{mM}$ fructose-6phosphate, $5 \mathrm{mM} \mathrm{MgCl}_{2}, 0.6 \mathrm{mM}$ ATP, $0.33 \mathrm{U} \mathrm{ml}^{-1}$ aldolase, 10 $\mathrm{U} \mathrm{ml}^{-1}$ triose phosphate isomerase, $1 \mathrm{U} \mathrm{ml}^{-1}$ glycerophosphate dehydrogenase and $0.2 \mathrm{mM} \mathrm{NADH}$ in Tris ( $\mathrm{pH}$ 7.6) buffer. Activity was monitored by measuring the formation of fructose-1,6-bisphosphate, as indicated by a coupled NADHdependent reduction of dihydroxyacetone phosphate to glycerol-3-phosphate, as the change in absorbance at $340 \mathrm{~nm}$ over $3 \mathrm{~min}$.

Malate dehydrogenase (MDH) activity was monitored using the procedure of Leprince et al. (1993a). Radicles (c. $5 \mathrm{mg}$ dry mass) were homogenized to a fine powder under liquid nitrogen using a mortar and pestle. Soluble proteins were extracted from frozen powder in $5 \mathrm{ml}$ of $50 \mathrm{mM}$ potassium phosphate buffer (pH 7.4) in the presence of $0.1 \%$ PVP (Siegel and Bing, 1956). The homogenate was then centrifuged at 8000 $g$ for $5 \mathrm{~min}$. An aliquot of $0.1 \mathrm{ml}$ of the supernatant was added to $2 \mathrm{ml}$ of $0.1 \mathrm{M}$ phosphate buffer ( $\mathrm{pH} 7.55$ ) and $0.1 \mathrm{ml}$ of $2 \mathrm{mg} /$ $\mathrm{ml} \mathrm{NADH}$. After $10 \mathrm{~min}, 0.1 \mathrm{ml}$ of $0.5 \mathrm{M}$ oxaloacetate in $0.1 \mathrm{M}$ phosphate buffer ( $\mathrm{pH}$ 7.0) was added. Activity was determined by observing the change in optical density of NADH at $340 \mathrm{~nm}$ over a 3 min period.

Oxidised nicotinamide adenine dinucleotide (NAD) assay

Radicles (c. $5 \mathrm{mg}$ dry mass) were homogenized in $5 \mathrm{ml}$ of 0.2 $\mathrm{M} \mathrm{HCl}$ following homogenization to a fine powder under liquid nitrogen in the mortar with a pestle, heated in a boiling water bath for $5 \mathrm{~min}$, cooled in an ice bath and centrifuged at $14000 \mathrm{~g}$ for $10 \mathrm{~min}$ (Zhao et al. 1987). An aliquot of $0.5 \mathrm{ml}$ of the supernatant was then transferred to $1.0 \mathrm{M}$ Bicine- $\mathrm{NaOH}$ buffer ( $\mathrm{pH}$ 8.0) and neutralised with $0.2 \mathrm{M} \mathrm{NaOH}$ in the dark (Matsumura and Miyachi, 1980). Following the addition of $0.1 \mathrm{ml}$ each of $40 \mathrm{mM}$ EDTA, $4.2 \mathrm{mM}$ 3-(4,5 dimethyl-thiazoyl2)-2,5-diphenyltetrazolium bromide (MTT), $16.6 \mathrm{mM}$ phenol ethosulfate and $5.0 \mathrm{M}$ ethanol, $0.1 \mathrm{ml}$ of $500 \mathrm{U} \mathrm{ml}^{-1}$ alcohol dehydrogenase was added after $5 \mathrm{~min}$ at $37{ }^{\circ} \mathrm{C}$. The level of NAD was determined by measuring the rate of reduction of MTT as absorbance at $570 \mathrm{~nm}$ after $30 \mathrm{~min}$.

Lipid peroxidation assessment

Lipids were extracted from radicles (c. $5 \mathrm{mg}$ dry mass) that had been homogenized under liquid nitrogen in a mortar with a pestle, in $5 \mathrm{ml}$ of dichloromethane/methanol $(2: 1 \mathrm{v} / \mathrm{v})$ containing butylated hydroxytoluene $\left(50 \mathrm{mg} \mathrm{l}^{-1}\right)$ according to Hailstones and Smith (1988) and modified as in Ntuli et al. (1997). Following centrifugation at $1500 \mathrm{~g}$ for $5 \mathrm{~min}, 1 \mathrm{ml}$ of $0.014 \mathrm{M}$ ferrous chloride $\left(\mathrm{FeCl}_{2}\right)$ was added to $2 \mathrm{ml}$ of the lipid extract in dichloromethane/methanol and shaken. Twenty $\mu \mathrm{l}$ of $30 \%$ potassium thiocyanate (KSCN) were then added. Hydroperoxide levels were estimated by the oxidation of $\mathrm{Fe}^{2+}$ as the absorbance recorded at $505 \mathrm{~nm}$.

\section{Antioxidant assays}

Superoxide dismutase (SOD), catalase (CAT) and glutathione reductase (GR) were extracted in $10 \mathrm{ml}$ of $50 \mathrm{mM}$ potassium phosphate ( $\mathrm{pH} 7.0), 0.25 \%(\mathrm{w} / \mathrm{v})$ Triton X-100 and $1 \%(\mathrm{w} / \mathrm{v})$ polyvinlypolypyrolidone, following homogenisation of radicles $($ c. $5 \mathrm{mg} \mathrm{dm}$ ) to a fine powder under liquid nitrogen in a mortar with a pestle, following the procedures of Mishra et al. $(1993 ; 1995)$. The homogenate was then centrifuged at 8 $000 \mathrm{~g}$ for $15 \mathrm{~min}$. For SOD, the reaction was performed with an aliquot of $2 \mathrm{ml}$ of the supernatant and $1 \mathrm{ml}$ of $50 \mathrm{mM}$ potassium phosphate $(\mathrm{pH}$ 7.8), $0.1 \mathrm{mM}$ EDTA containing $18 \mu \mathrm{M}$ cytochrome $c$ and $0.1 \mathrm{mM}$ xanthine and the reaction started with addition of $0.02 \mathrm{ml}$ of $1 \mathrm{U} \mathrm{ml}^{-1}$ of xanthine oxidase (McCord and Fridovich, 1969; Schoner and Krause, 1990). Activity was monitored by measuring the rate of reduction of cytochrome $\mathrm{c}$ as the change in absorbance at $550 \mathrm{~nm}$.

CAT was assayed in an aliquot of $2 \mathrm{ml}$ of the supernatant added to $1 \mathrm{ml}$ of $50 \mathrm{mM}$ potassium phosphate containing $11 \mathrm{mM} \mathrm{H}_{2} \mathrm{O}_{2}(\mathrm{pH}$ 7.0). Activity was determined as the decomposition of $\mathrm{H}_{2} \mathrm{O}_{2}$ by the decrease in absorbance at 240 nm (Aebi, 1983).

GR was assayed in an aliquot of $2 \mathrm{ml}$ of the supernatant added to $1 \mathrm{ml}$ of $25 \mathrm{mM}$ Tris- $\mathrm{HCl}$ containing $0.5 \mathrm{mM}$ oxidised glutathione (GSSG) and $0.12 \mathrm{mM}$ NADPH (pH 7.8) (Foyer and Halliwell, 1976). Activity was recorded by measuring the oxidation of NADPH as the decrease in absorbance at $340 \mathrm{~nm}$.

AsA was extracted in $4 \mathrm{ml}$ of $2.5 \mathrm{mM}$ perchloric acid $\left(\mathrm{HClO}_{4}\right)$ following homogenization of radicles (c. $5 \mathrm{mg} \mathrm{dm}$ ) in liquid nitrogen in the mortar with a pestle according to Foyer et al. (1983). The homogenate was then centrifuged at $8000 \mathrm{~g}$ for $5 \mathrm{~min}$ and neutralized to $\mathrm{pH} 5.6$ with $1.25 \mathrm{M}$ $\mathrm{K}_{2} \mathrm{CO}_{3}$. One $\mathrm{ml}$ of the extract was transferred to $1 \mathrm{ml}$ of $0.1 \mathrm{M}$ sodium phosphate buffer ( $\mathrm{pH} 5.6$ ) and the reaction started with addition of $1 \mathrm{ml}$ of $5 \mathrm{U} \mathrm{ml}^{-1}$ of ascorbate oxidase (Hewitt and Dickes, 1961). The level of AsA was estimated by measuring its oxidation as the decrease in absorbance at $265 \mathrm{~nm}$.

For all the biochemical assays, the extractions were performed on five radicles (c. $5 \mathrm{mg} \mathrm{dm}$ ) in at least three replicates at $4{ }^{\circ} \mathrm{C}$. All the assays were carried out at $25{ }^{\circ} \mathrm{C}$. All chemicals were bought from Sigma and the units are as defined therein. Results are reported as means $\pm \mathrm{SE}$ of the replicate extractions and $\%$ change of the initial value.

\section{Dry mass estimations}

For the conductivity tests and all biochemical assays, dry mass was calculated from wet mass and water contents expressed on a dry mass basis. Wet mass was determined before the tests or assays were conducted.

\section{Statistical analysis}

Data were subjected to one-way ANOVA test. Where significant effects were found to occur, the Tukey multiple range test was subsequently used to distinguish significantly deviating means.

\section{RESULTS}

\section{Desiccation kinetics}

Radicles of P. sativum seeds were at a water content of c. 2.0 $\mathrm{g}_{2} \mathrm{O} / \mathrm{g}$ dry matter $\left(\mathrm{g} \mathrm{g}^{-1} \mathrm{dm}\right.$ ) after imbibition (data not shown). Radicles of different lengths showed different drying curves (data not shown). Radicles reached a water content of $c$. $4.5 \mathrm{~g} \mathrm{~g}^{-1} \mathrm{dm}$ following germination subsequent to imbibition (data not shown). The rate of water loss could be described by exponential and modified inverse functions for both drying regimes. 
Radicles reached a water content of c. $0.19 \mathrm{~g} \mathrm{~g}^{-1} \mathrm{dm}$ in 24 $\mathrm{h}$ ( $\beta$ [rate constant of water loss/drying rate [Liang and Sun, 2000; Sun, 2002\}] $=1.4, \mathrm{r}^{2}=0.75$ and $\mathrm{p}=0.01 ; b=1.05 \mathrm{~h}, \mathrm{r}^{2}=$ 0.99 and $p<0.01$ ) following rapid drying (Fig. 1). In contrast, slow dehydration achieved a final water content of $c .0 .22 \mathrm{~g}$ $\mathrm{g}^{1} \mathrm{dm}$ in 7 days $\left(\beta=0.19, \mathrm{r}^{2}=0.58\right.$ and $\mathrm{p}=0.24 ; b=8.25 \mathrm{~h}$, $\mathrm{r}^{2}=0.83$ and $\mathrm{p}=0.09$ ). Thus, rapid dehydration facilitated desiccation approximately seven times more rapidly than slow dying. Conversely, the water content of the radicles remained constant at c. $4.5 \mathrm{~g} \mathrm{~g}^{-1} \mathrm{dm}$ over four weeks $\left(\beta=0, \mathrm{r}^{2}=0.09\right.$ and $\mathrm{p}=0.70)$ during wet storage (data not shown).

\section{Viability}

Viability, as assessed by germination capacity and tetrazolium staining, of fresh (undried) P. sativum radicles was $100 \%$. It remained at that level throughout rapid drying (Fig. 2A). However, there was a precipitous decline in viability at $c$. $0.26 \mathrm{~g} \mathrm{~g}^{-1} \mathrm{dm}$ following slow desiccation. Similarly, there was a gradual decrease in viability after two weeks of hydrated storage (Fig. 2B).

\section{Electrolyte leakage}

Untreated radicles of $P$. sativum recorded a mean electrolyte leakage of c. $47 \mathrm{mS} \mathrm{cm}^{-1} \mathrm{~g}^{-1} \mathrm{dm}$ after $12 \mathrm{~h}$. Subsequently there was a progressive increase in electrolyte leakage with drying and wet storage (Figs 2C and D). The highest conductivity readings for radicles that were dried rapidly and slowly were c. 68.5 and c. $122 \mathrm{mS} \mathrm{cm}^{-1} \mathrm{~g}^{-1} \mathrm{dm}$, respectively. Radicles dried slowly registered more leakage than those dried rapidly at a corresponding water content.

\section{Respiratory metabolism}

There was a c. $26 \%$ decrease and a $50 \%$ increase in the activity of PFK before the onset of viability loss with rapid and slow desiccation (at c. 0.19 and $0.26 \mathrm{~g} \mathrm{~g}^{-1} \mathrm{dm}$ ), respectively (Fig

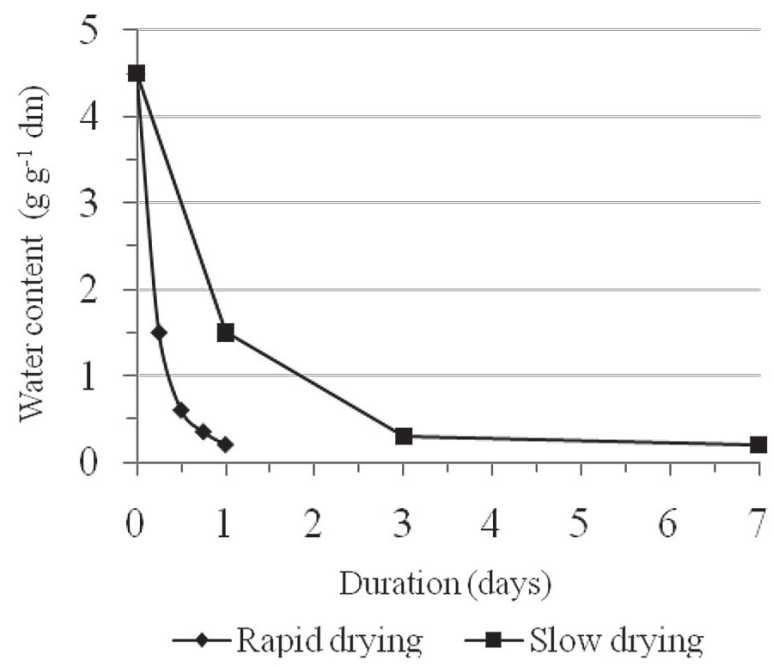

Figure 1. Water contents of embryonic radicles of Pisum sativum during slow and rapid desiccation. (Error bars represent means \pm $\mathrm{SE}, \mathrm{n}=5$, all smaller than symbols).
3A). During viability loss there was a c. $41 \%$ decrease in PFK activity upon slow drying. There was no significant change in the activity of PFK prior to the onset of or during viability loss with hydrated storage (Fig. 3B).

A c. $42 \%$ and a c. $75 \%$ reduction in the activity of $\mathrm{MDH}$ were observed before the onset of viability loss upon rapid and slow dehydration, respectively (Fig. 3C). A c. 54\% decline in the activity of MDH preceded the onset of viability loss during wet storage (Fig. 3D). A further c. $21 \%$ decrease in $\mathrm{MDH}$ activity accompanied loss of viability during wet storage.

The levels of NAD were enhanced by c. $87 \%$ before the onset of loss of viability upon rapid dehydration (Fig. 3E). A c. $30 \%$ reduction in NAD levels preceded the onset of loss of viability as slow desiccation proceeded. A c. $102 \%$ increase in the levels of NAD accompanied loss of viability during slow drying. Loss of viability was preceded by a c. $43 \%$ decline in the levels of NAD during wet storage (Fig. 3F). No significant change in the level of NAD accompanied the period of loss of viability during hydrated storage.

\section{Hydroperoxide levels}

An initial c. $52 \%$ and a subsequent c. $64 \%$ decrease in level of hydroperoxides preceded the onset of loss of viability during rapid dehydration (Fig. 3G). No significant change in the level of hydroperoxides accompanied loss of viability during slow desiccation. The onset of loss of viability was preceded by a $c$. $72 \%$ increase in the hydroperoxide levels during wet storage (Fig. $3 \mathrm{H})$. No significant change in the level of hydroperoxides accompanied the period of loss of viability during hydrated storage.

\section{Antioxidant levels}

There was an initial c. $46 \%$ decrease and a subsequent $c$. $38 \%$ increase in the activity of SOD before the onset of loss of viability during rapid dehydration (Fig. 4A). In contrast, there was a c. $120 \%$ stimulation in SOD activity before the onset of viability loss following slow drying. During loss of viability there was a c. $88 \%$ decrease in SOD activity with slow dehydration. There was a c. $142 \%$ enhancement in the activity of SOD prior to the onset of viability loss during wet storage (Fig. 4B). Viability loss was not accompanied by significant change in SOD activity during hydrated storage. There were no significant changes in CAT activity during drying and wet storage (Fig. 4C and D).

The activity of GR initially increased by c. $93 \%$ and was then subsequently stimulated by c. $151 \%$ before the onset of viability loss during rapid drying (Fig. 4E). In contrast, GR activity was initially diminished by c. $68 \%$ and subsequently increased by c. $113 \%$ prior to the onset of viability loss upon slow dehydration. Loss of viability did not produce significant change in GR activity upon slow desiccation. The onset of loss of viability was preceded by a c. $248 \%$ stimulation in GR activity during wet storage (Fig. 4F). However, no further significant change in GR activity accompanied the period of viability loss with hydrated storage.

There was an initial c. $51 \%$ decrease and a subsequent $c$. $51 \%$ increase in the levels of AsA before the onset of viability loss during rapid drying (Fig. 4G). Similarly, an initial c. 30\% decrease and a c. $28 \%$ increase in AsA levels preceded the onset of and accompanied loss of viability upon slow dehydration, 
respectively. During wet storage, levels of AsA did not change significantly during the experimental period (Fig $4 \mathrm{H}$ ).

\section{DISCUSSION}

Water loss during desiccation of radicles of $P$. sativum can be described by exponential and modified inverse functions (Ntuli and Pammenter, 2009). In this regard, it should be remembered that the difference in water potentials between the cell and the surrounding air, which drives water loss, is exponentially related to the relative humidity of the surrounding air through the water vapour pressure (Wexler, 1997).

In contrast, the water content of radicles of $P$. sativum remained constant during wet storage as the surrounding air is fully hydrated and there is no direct contact between the radicles and the water. Hence, water loss from the seed to the surrounding air and water uptake by the radicles are in equilibrium.

In agreement with studies on other species (Berjak et al., 1984; Farrant et al., 1985; 1989; Grabe, 1989; Pritchard, 1991; Pammenter et al., 1998; Ntuli et al., 2011), germination and tetrazolium tests revealed that rapid dehydration of radicles of hydrated pea seeds markedly decreased the water content at which abrupt viability loss occurred in comparison with slow desiccation.
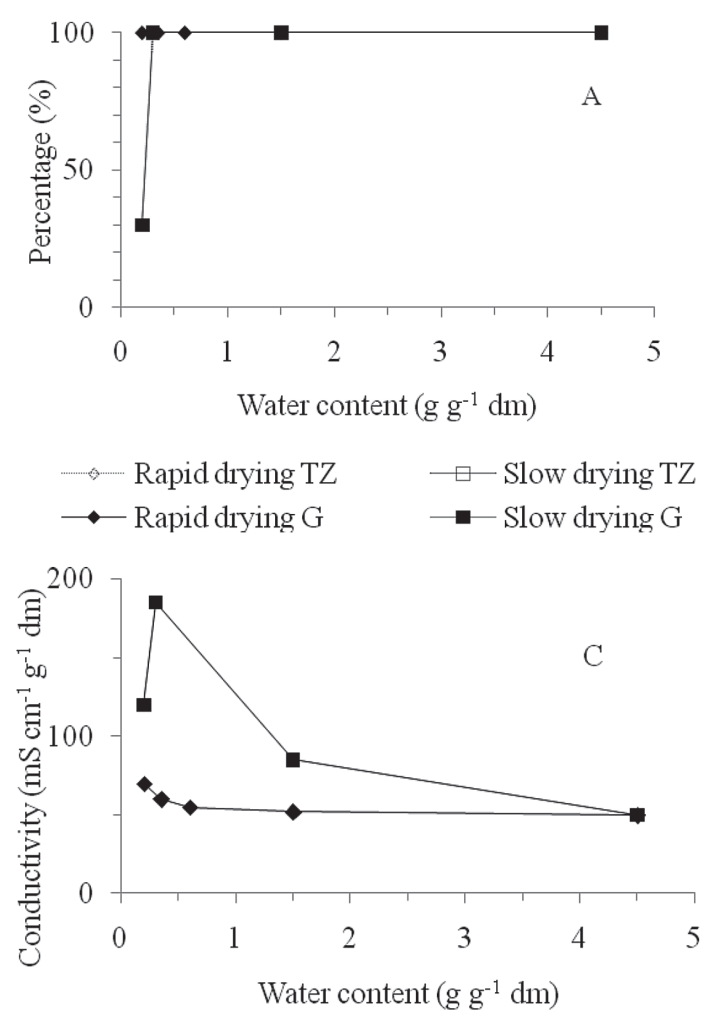

Rapid drying $\rightarrow$-Slow drying
Loss of viability occurred at low $\left(\leq 0.5 \mathrm{~g} \mathrm{~g}^{-1} \mathrm{dm}\right)$ water contents during slow dehydration of radicles of $P$. sativum. This observation indicates that desiccation damage (sensu stricto) underlies loss of viability during slow desiccation in radicles of $P$. sativum. In wet storage, viability also began to decline after two weeks, suggesting that ageing may have also contributed to viability loss during slow drying.

In the present study, the relationship between electrolyte leakage and water content during drying did not show the typical pattern in which there is constant leakage to a critical water content, at which point a sudden increase is observed (e. g. Pammenter et al., 1991). Rather, there was a gradual increase in the degree of leakage as drying proceeded. Pammenter et al. (1998) and Ntuli et al. (2011) showed a similar pattern during drying of whole seeds of Ekebergia capensis and excised radicles of Quercus robur. Nevertheless, less electrolyte leakage was observed during rapid than slow drying. It is suggested that less membrane damage occurred during rapid dehydration because of the limited period of exposure to stress compared with slow desiccation.

The activities of PFK and MDH were reported to be adversely affected by desiccation (Leprince et al., 1993a; reviewed by Côme and Corbineau, 1996; Song et al., 2009; Ntuli et al., 2011). PFK activity decreased upon rapid drying but was stimulated during slow dehydration. This apparent anomaly is attributed to the minimally desiccation-sensitive
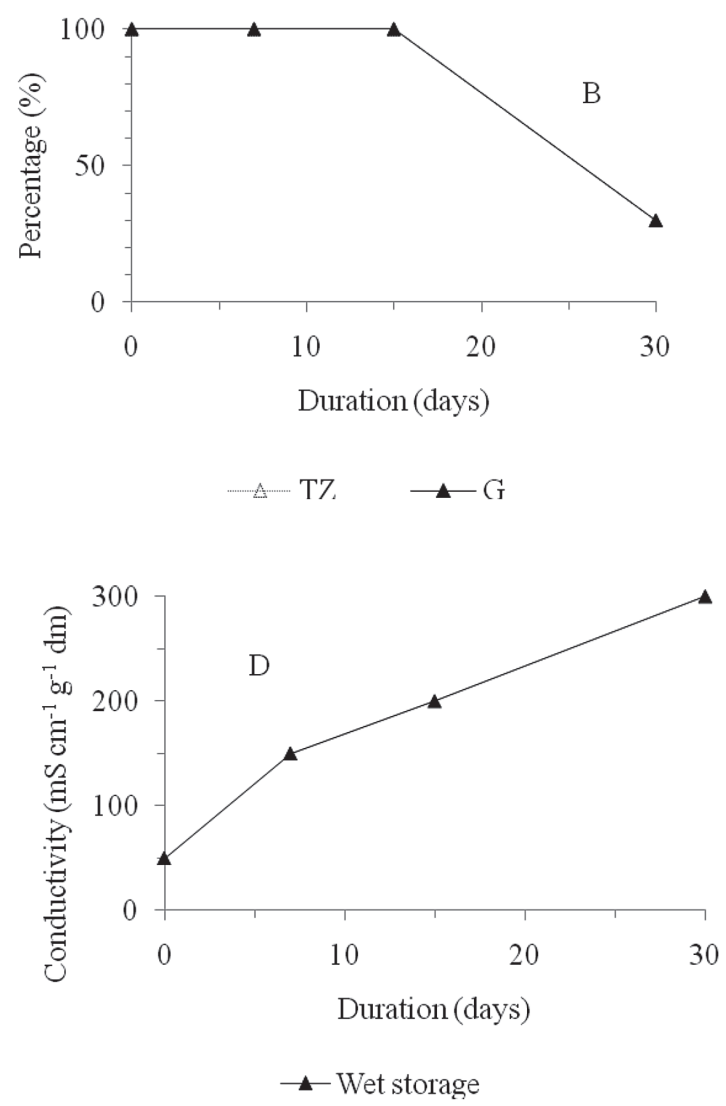

Figure 2. Viability, as assessed by tetrazolium staining (open symbols and dotted lines), germination capacity (closed symbols and solid lines) and maximum electrolyte leakage of $P$. sativum radicles following slow and rapid dehydration (A and $C$ ) or hydrated storage (B and D). (Error bars represent means $\pm S E, n=10$, all smaller than symbols). The TZ test gave exactly the same results as germination assay so the TZ data are not visible on these figs. 


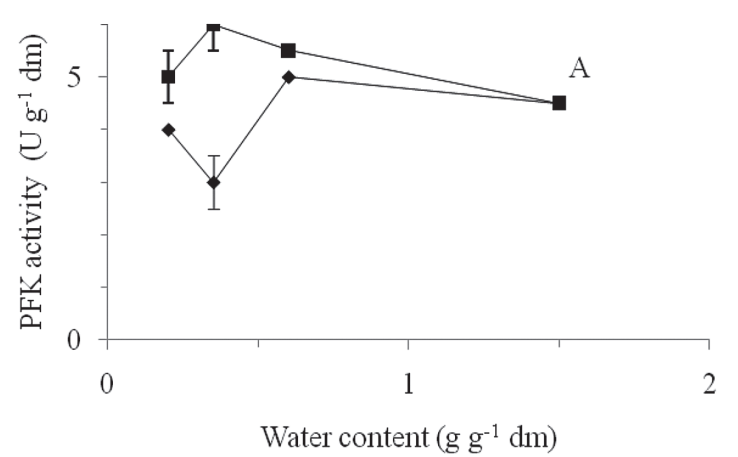

$\rightarrow$ Rapid drying $\rightarrow$-Slow drying

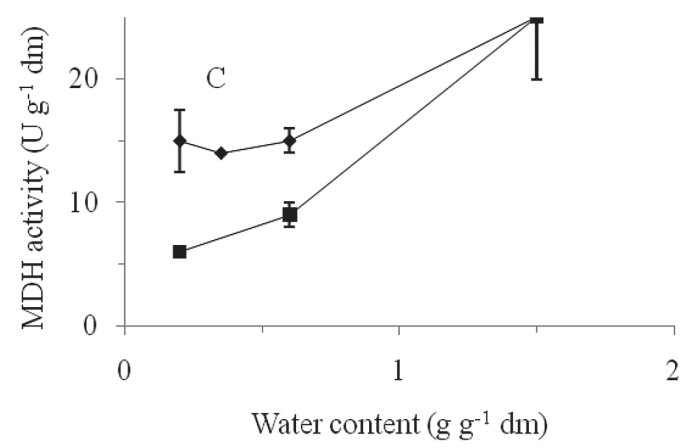

$\bullet$ Rapid drying $\rightarrow-$ Slow drying

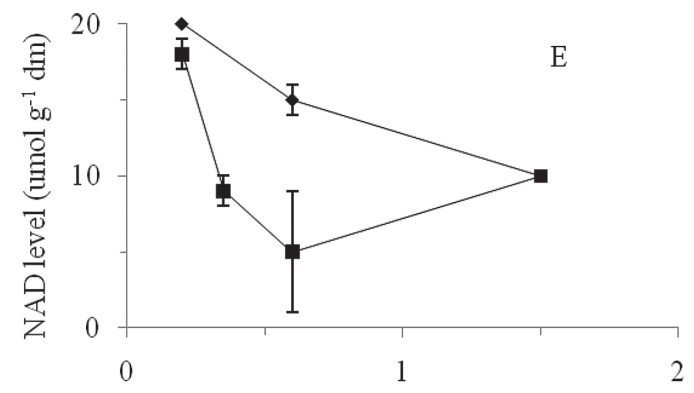

Water content $\left(\mathrm{g} \mathrm{g}^{-1} \mathrm{dm}\right)$

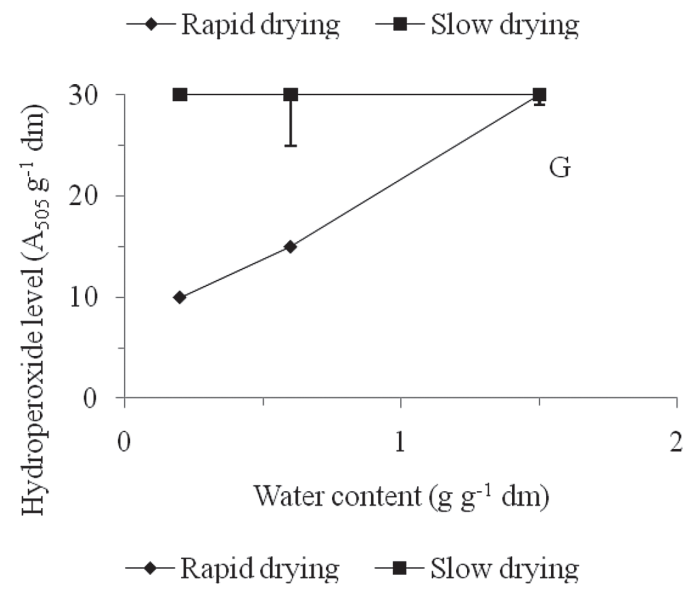

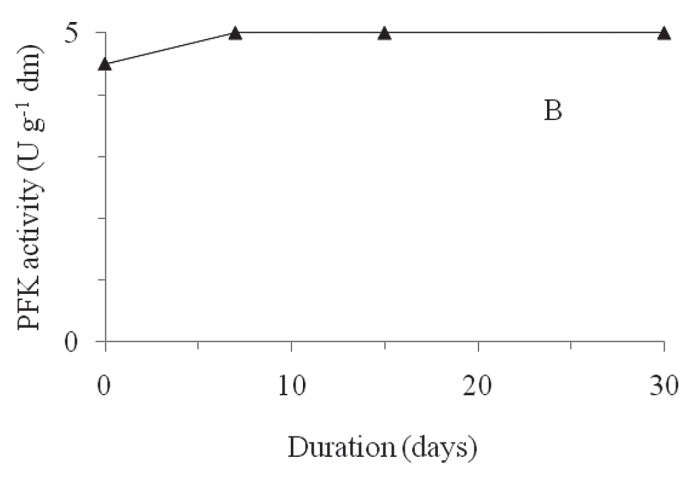
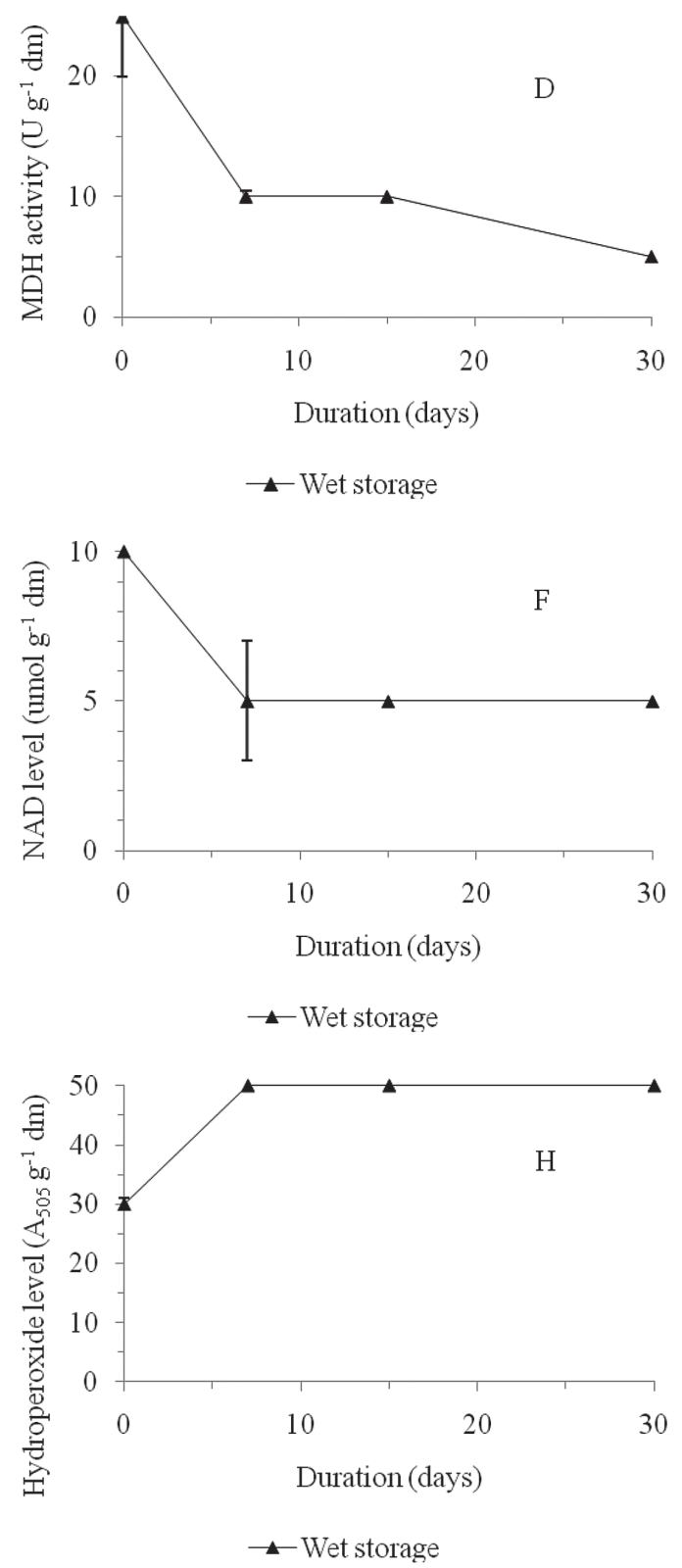

Figure 3. Activities of phosphofructokinase and malate dehydraogenase and levels of NAD and hydroperoxides in radicles of $P$. sativum during dehydration at different rates $(A, C, E$ and $G$ ) or wet storage $(B, D, F$ and $H)$. ( $1 \mathrm{U}$ of PFK will convert $1 \mu$ mol of fructose-6phosphate and ATP to fructose-1,6-bisphosphate and ADP per minute at $\mathrm{pH} 8.0$ at $30{ }^{\circ} \mathrm{C}$ and $1 \mathrm{U}$ of $\mathrm{MDH}$ will convert $1 \mu \mathrm{mol}$ of oxaloacetate and NADH to malate and NAD per minute at $\mathrm{pH} 7.5$ at $25{ }^{\circ} \mathrm{C}$. Error bars represent means $\pm \mathrm{SE}$, $\mathrm{n}=3$, some smaller than symbols). 


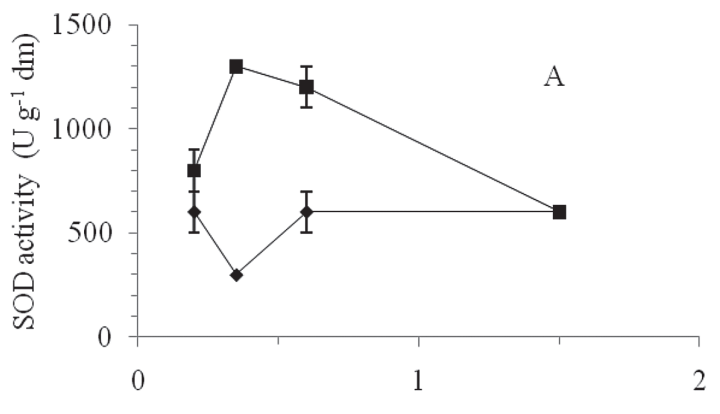

Water content $\left(\mathrm{g} \mathrm{g}^{-1} \mathrm{dm}\right)$

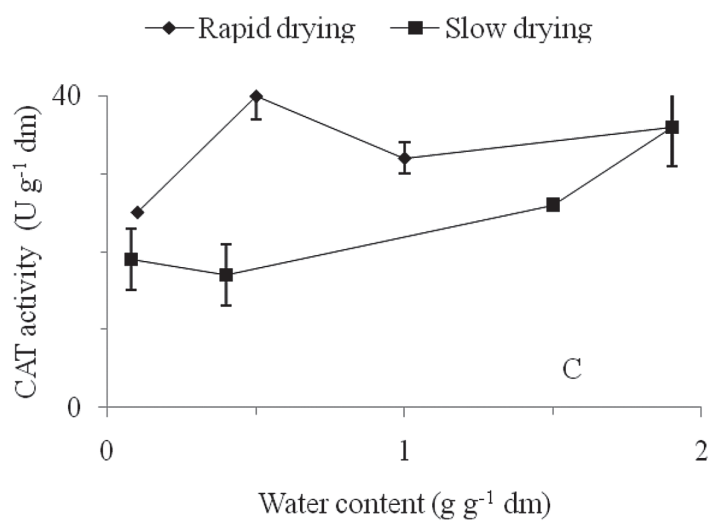

$\rightarrow-$ Rapid drying $\rightarrow$ - Slow drying

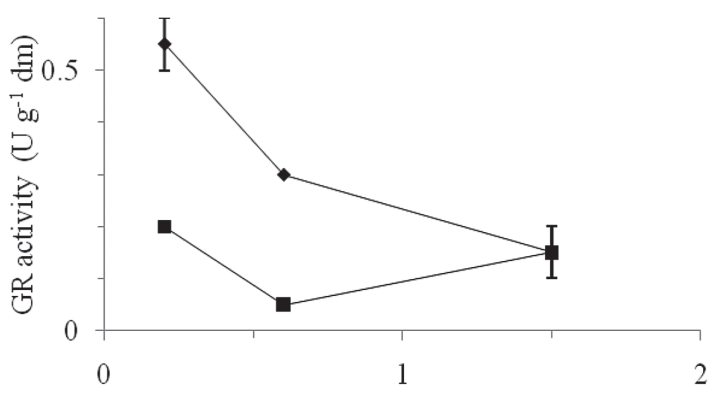

Water content $\left(\mathrm{g} \mathrm{g}^{-1} \mathrm{dm}\right)$

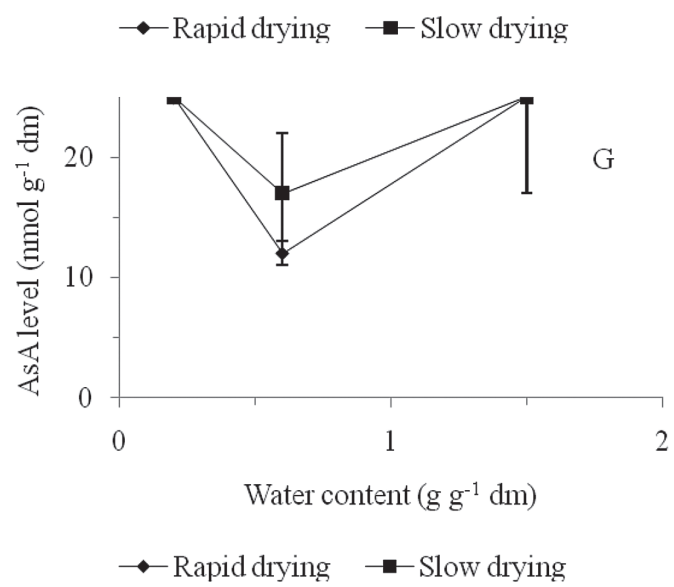

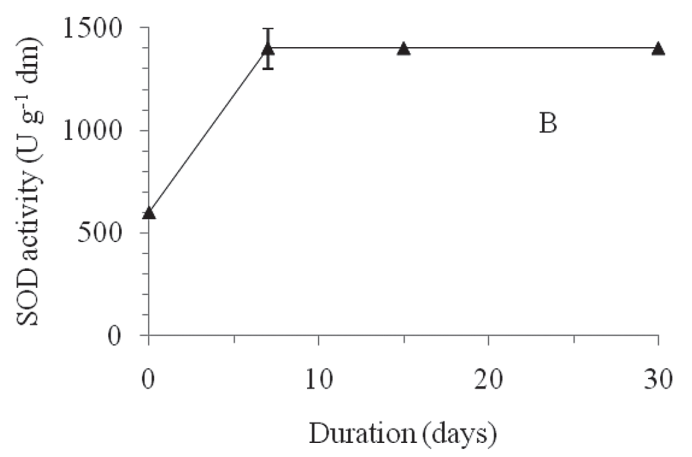

$\rightarrow$ Wet storage
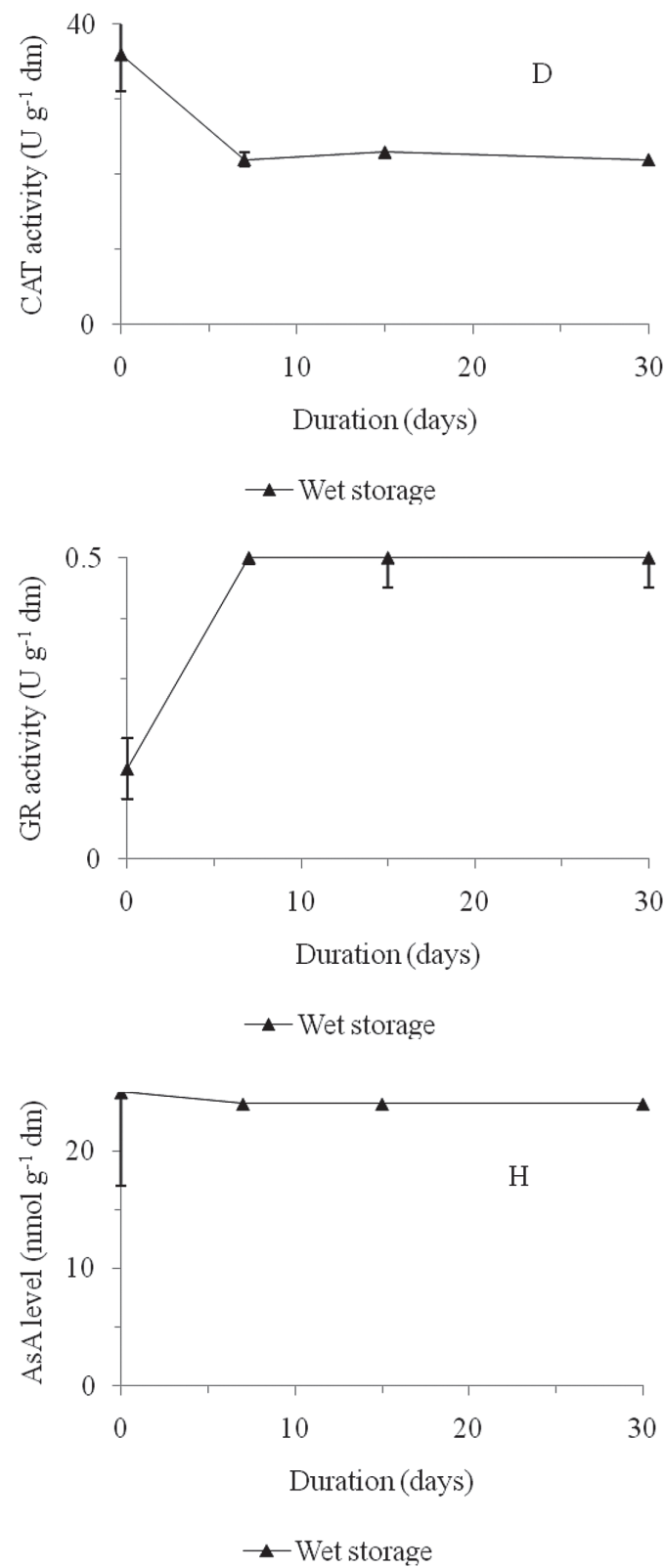

Figure 4. Activities of superoxide dismutase, catalase and glutathione reductase and levels of ascorbate in radicles of $P$. sativum during desiccation at different rates (A) or wet storage (B). ( $1 \mathrm{U}$ of SOD will inhibit the rate of reduction of cytochrome $c$ by $50 \%$ in a coupled system with xanthine and xanthine oxidase at $\mathrm{pH} 7.8$ at $25^{\circ} \mathrm{C}, 1 \mathrm{U}$ of CAT will decompose $1 \mu \mathrm{mol}$ of hydrogen peroxide $\left(\mathrm{H}_{2} \mathrm{O}_{2}\right)$ per minute at pH 7.0 at $25^{\circ} \mathrm{C}$, while the concentration of $\mathrm{H}_{2} \mathrm{O}_{2}$ falls from 10.3 to $9.2 \mathrm{mM}$ and $1 \mathrm{U}$ of GR will reduce $1 \mu$ mol of oxidized glutathione per minute at $\mathrm{pH} 7.6$ at $25^{\circ} \mathrm{C}$. Error bars represent means $\pm \mathrm{SE}, \mathrm{n}=3$, some smaller than symbols). 
nature of radicles which have just begun germination, which allows the accumulation of the enzyme with passage of time and the relative tolerance of the enzyme to water stress. During wet storage there was no significant change in the activity of PFK. Expectedly, a decline in MDH activity occurred during desiccation and wet storage.

Following drying of germinating maize seeds, impairment of mitochondrial electron transport chain was marked in the NADH dehydrogenase of NADH-coenzyme $Q$ reductase (complex I) and NADH-cytochrome $c$ reductase (complex IV) and the alternative oxidase (Leprince et al., 1993a; 1994; 1995; 2000; reviewed by Côme and Corbineau, 1996; Leprince and Hoekstra, 1998; Song et al., 2009). In the present investigation, the level of NAD was surprisingly enhanced during drying. In contrast, it declined upon hydrated storage. The increase in NAD levels during dehydration is attributed to the minimally desiccation-sensitive nature of pea seeds which have just entered germination. It is also possible that the increase in NAD levels during the period of viability loss upon slow drying is a result of spontaneous NADH oxidation in dead tissue. It is suggested that the decrease in NAD levels during wet storage is a result of the impairment of the NADH dehydrogenases of the electron transport chain complexes I and IV as shown in the aforementioned studies.

An increase in the level of hydroperoxides was recorded in germinating seeds of maize and excised radicles of forest mahogany, Chinese wampee and English oak during desiccation (Leprince et al., 1990 and Song et al., 2005; Huang et al., 2009; Ntuli et al., 2011, respectively). Surprisingly, there was a decrease in hydroperoxide levels during rapid dehydration in the present study. However, slow drying and hydrated storage resulted in no significant change and an increase in levels of hydroperoxides respectively.

Like germinating orthodox seeds, it appears that the patterns of physiological and biochemical response of the free radical processing systems in desiccation-sensitive seeds to oxidative stress differ among both tissues and species. For instance, the defense against oxidative attack on axial tissue of Quercus robur was largely dependent on antioxidants whereas it was predominantly enzymatic in cotyledons (Hendry et al., 1992). Moreover, the activities of SOD and GR in radicles decreased during desiccation (Hendry et al., 1992). In contrast, SOD and GR activity increased in the cotyledons upon drying. Furthermore, there was a decrease in the levels of $\alpha$-tocopherol in radicles during dehydration compared to an increase in the cotyledons (Hendry et al., 1992). However, the activity of SOD increased significantly during drying in Shorea robusta seeds (Chaitanya and Naithani, 1994) but there was a rapid decrease in activities of SOD and peroxidases in Theobroma cacoa radicles corresponding to loss of viability (Li and Sun, 1999). Additionally, an increase in both the amount of tocopherol and activity of SOD was observed in the plumule of radicles of Avicennia marina following dehydration (Greggains et al., 2001).

The activity of SOD did not change significantly during rapid desiccation in the present study. In contrast, it increased upon slow drying and hydrated storage. Similarly, CAT activity did not change significantly during dehydration and wet storage. The activity of GR increased upon desiccation and hydrated storage. No significant changes in the levels of AsA accompanied viability loss during drying and wet storage. It is suggested that the increase in GR activity during rapid drying led to the decrease in hydroperoxide levels.
Nonetheless the increases in the activities of SOD and GR during slow drying or wet storage could not bring down the levels of hydroperoxides, which stayed constant or increased, respectively.

In summary, the respiratory enzyme $\mathrm{MDH}$ of radicles of $P$. sativum showed sensitivity to desiccation and wet storage. Dehydration surprisingly enhanced the activities of PFK and the NADH dehydrogenases of the electron transport chain complexes I and IV. These data are consistent with the view that these events led to metabolic imbalance which, in turn, resulted in more leakage of electrons than normal from the mitochondrial electron transport chain. The increased free radical activity caused the enhanced formation of hydroperoxides during lipid peroxidation. In addition, desiccation and wet storage impaired the efficiency of the free radical processing systems. This situation is less prevalent during rapid drying than slow dehydration and hydrated storage, hence there were lower critical water contents with rapid desiccation.

In conclusion, the results of the present study support the hypothesis that rapid dehydration lowers the critical water content for the survival of desiccation-sensitive seeds. Furthermore, they show that such a phenomenon arises as a consequence of lesser adverse effects upon metabolism and free radical processing systems when drying is more rapid. In addition, they demonstrate that radicles are a readilyavailable useful model to study desiccation-sensitivity in plants, especially seed tissues. However, caution is advised in transference of observations based on model systems - germinating and detached radicles - and other systems recalcitrant seed and vegetative tissues and attached radicles

\section{ACKNOWLEDGEMENTS}

The technical assistance, expert advice of A. M. Motha; P. Berjak, N. W. Pammenter and M. T. Smith and the financial assistance of the National Research Foundation of South Africa are gratefully acknowledged.

\section{LITERATURE CITED}

AEBI HE (1983) Catalase. In: Bergmeyer HU, Bergmeyer J, Grabe M (eds) Methods of Enzymatic Analysis, Volume III. Verlag Chemie, Weinheim. pp. 273-286.

BERJAK P (2006) Unifying perspectives of some mechanisms basic to desiccation tolerance across life forms. Seed Sci. Res. 16, 1-15.

BERJAK P, PAMMENTER NW (1997a) Progress in the understanding and manipulation of desiccation-sensitive (reclacitrant) seeds. In: Ellis RM, Black M, Murdoch AJ, Hong TD (eds) Basic and applied aspects of seed biology. Dordrecht, Kluwer Academic Publishers. pp. 689-703.

BERJAK P, PAMMENTER NW (1997b) Important considerations pertaining to desiccation-sensitivity of seeds (recalcitrant seed behaviour) In: Edwards DGW, Naithani SC (eds) Seed and nursery technology of forest trees (Proceeding of the IUFRO Symposium 1997). New Age International (P) Limited, Publishers. New Dehli, India. pp. 43-69.

BERJAK P, PAMMENTER NW (2001) Seed recalcitrance - current perspectives. S. Afr. J. Bot. 67, 79-89.

BERJAK P, PAMMENTER, NW (2004) Recalcitrant seeds. In: Benech-Arnold RL, Sánchez RA Seed physiology: Applications to agriculture. Haworth Press. pp. 305-345.

BERJAK P, PAMMENTER NW (2008) From Avicennia to Zizania: Seed recalcitrance in perspective. Ann. Bot. 101, 213-228.

BERJAK P, DINI M, PAMMENTER NW (1984) Possible mechanisms underlying the differing dehydration responses in recalcitrant and orthodox seeds. Desiccation-associated subcellular changes in propagules of Avicennia marina. Seed Sci. Tech. 12, 365-384. 
BERJAK P, FARRANT JM, PAMMENTER NW (1989) The basis of recalcitrant seed behaviour: cell biology of the homoiohydrous seed condition. In: Taylorson RB (ed) Recent advances in the development and germination of seeds. Plenum Press, New York and London. pp. 89-108.

BERJAK P, VERTUCCI CW, PAMMENTER NW (1993) Effects of developmental status, and dehydration rate on characteristics of water and desiccation sensitivity in recalcitrant seeds of Camellia sinensis. Seed Sci. Res. 3, 155-166.

BUITINK J, HOEKSTRA FA, LEPRINCE O (2002). Biochemistry and biophysics of tolerance systems. In: Black M, Pritchard HW (eds) Desiccation and survival in plants: drying without dying. CAB International, Wallingford, UK. pp. 293-318.

CARPENTER JF, CROWE LM, CROWE, JH (1987) Stabilisation of phosphofructokinase with sugars during freeze-drying: characterisation of enhanced protection in the presence of divalent cations. Biochem. Biophys. Acta 923, 109-115.

CHAITANYA KSK, NAITHANI SC (1994) Role of superoxide, lipid peroxidation and speroxide dismutase in membrane perturbation during loss of viability in seeds of Shorea robusta Gaertn. F. New Phytol. $126,623-627$.

CLOSE TJ (1996) Dehydrins: emergence of biochemical role of a family of plant dehydration proteins. Physiol. Plant. 97, 795-803.

CÔME D, CORBINEAU F (1996). Metabolic damage related to desiccation sensitivity. In: Ouédraogo AS, Poulsen K, Stubsgaard F. (eds) Intermediate/recalcitrant tropical forest tree seeds. Proceedings of a workshop on improved methods for handling and storage of intermediate/recalcitrant tropical forest tree seeds, Humlebaek, Denmark. IPGRI, Rome and DANIDA, Humlebaek, Denmark. pp. 107-120.

CROWE JH, HOEKSRTA FA, CROWE LM (1992) Anhydrobiosis. Ann. Rev. Phys. 54, 579-599.

FARRANT JM, BERJAK P, PAMMENTER NW (1985) The effect of drying rate on viability retention of recalcitrant propagules of Avicennia marina. S. Afr. J. Bot. 51, 432-438.

FARRANT JM, PAMMENTER NW, BERJAK P (1989). Germinationassociated events and the desiccation sensitivity of recalcitrant seeds - a study of three unrelated species. Planta 178, 189-198.

FINCH-SAVAGE WE, GRANGE RI, HENDRY GAF, ATHERTON NM (1993) Embryo water status and loss of viability during desiccation in the recalcitrant species Quercus robur L. In: Côme, D, Corbineau, F (eds) Fourth international workshop on seeds, basic and applied aspects of seed biology. ASFIS, Paris. pp. 723-730.

FOYER CH, HALLIWELL B (1976) The presence of glutathione and glutathione reductase in chloroplasts: A proposed role in ascorbic acid metabolism. Planta 133, 21-25.

FOYER C, ROWELL J, WALKER D (1983) Measurement of the ascorbate content of spinach leaf protoplasts and chloroplasts during illumintion. Planta 157, 239-244.

GRABE, DF (1989) Report of the seed moisture committee. Seed Sci. Tech. 7 (Supplement 1), 87-93.

GREGGAINS V, FINCH-SAVAGE WE, ATHERTON NM, BERJAK P (2001) Viability loss and free radical processes during desiccation of recalcitrant Avicennia marina seeds. Seed Sci. Res. 11, 235-242.

HAISLTONES MD AND SMITH MT (1988) Lipid peroxidation in relation to declining vigour in seeds of soya (Glycine max L.) and cabbage (Brassica oleracea L.). J. Plant Physiol. 133, 452-456.

HENDRY GAF (1993) Oxygen, free radical processes and seed longevity. Seed Sci. Res. 3,141-153.

HENDRY GAF, FINCH-SAVAGE WE, THORPE PC, ATHERTON NM, BUCKLAND SM, NILSSON KA, SEEL WE (1992) Free radical processes and loss of viability during desiccation in the recalcitrant species Quercus robur L. New Phytol. 122, 273-279.

HEWITT EJ, DICKES GJ (1961) Spectrophotometric measurements on ascorbic acid and their use for the estimation of ascorbic acid and dehydroacsorbic acid in plant tissue. Biochem. J. 78: 384-391.

HOFMANN E, KOPPERSCHLÄGER G (1982) Phosphofructokinase in yeast. Methods Enzymol. 90: 1073-1079.

HORBOWICZ M, OBENDORF RL (1994) Seed desiccation tolerance and storability: dependence on flatulence-producing oligosaccharides and cyclitols - review and survey. Seed Sci. Res. 4, 385-405.

HUANG H, SONG SQ, WU XJ (2009) Response of Chinese wampee radicles and maize embryos to dehydration at different rates. J Integr. Plant Biol. 51, 67-74.

INTERNATIONAL SEED TESTNG ASSOCIATION (1996) International rules for seed testing. Seed Sci. Tech. 24, Suppliment 1.

LEPRINCE O, GOLOVINA EA (2002) Biochemical and biophysical methods for quantifying desiccation phenomena in seeds and vegetative tissues.
In: Black M, Pritchard HW (eds) Desiccation and survival in plants: drying without dying. CAB International, Wallingford, UK. pp. 111-146.

LEPRINCE O, HOEKSTRA FA (1998) The response of cytochrome redox state and energy metabolism to dehydration support a role for cytoplasmic viscosity in desiccation tolerance. Plant Physiol. 118, 1253-1264.

LEPRINCE O, ATHERTON NM, DELTOUR R, HENDRY GAF (1994) The involvement of respiration in free radical processes during loss of desiccation tolerance in germinating Zea mays L.: an electron paramagnetic resonance study. Plant Physiol. 104, 1333-1339.

LEPRINCE O, BUITINK J, HOEKSTRA FA (1999) Radicles and cotyledons of recalcitrant seeds of Castenea sariva Mil. exhibit contrasting responses of respiration to desiccation sensivity. J. Exp. Bot. 338, 1515-1524.

LEPRINCE O, DELTOUR R, HENDRY GAF (1993a) Impaired NADPH metabolism during loss of desiccation tolerance in germinating Zea mays seeds. In: Côme D, Corbineau F (eds) Fourth international workshop on seeds: basic and applied aspects of seed biology. ASFIS, Paris. pp. 393-397.

LEPRINCE O, DELTOUR R, HENDRY GAF (1993b) The mechanisms of desiccation tolerance in developing seeds. Seed Sci. Res. 3, 231-246.

LEPRINCE O, DELTOUR R, THORPE PC, ATHERTON NM, HENDRY GAF (1990) The role of free radicals and radical processing systems in loss of desiccation tolerance in germinating maize (Zea mays L.). New Phytol. 116, 573-580.

LEPRINCE O, HARREN FJM, BUITINK J, ALBERDA M, HOEKSTRA FA (2000) Metabolic dysfunction and unabated respiration precede the loss of membrane integrity during dehydration of germinating radicles. Plant Physiol. 122, 597-608.

LEPRINCE O, VAN DER WERF A, DELTOUR R, LAMBERS H (1992) Respiratory pathway in germinating maize radicles correlated with desiccation tolerance and soluble sugars. Physiol. Plant. 85, 581-588.

LEPRINCE O, VERTUCCI CW, HENDRY GAF, ATHERTON NM (1995) The expression of desiccation-induced damage in orthodox seeds is a function of oxygen and temperature. Physiol. Plant. 94: 233-240.

LI C, SUN WQ (1999) Desiccation sensitivity and activities of free radicalscavenging enzymes in recalcitrant Theobroma cacao seeds. Seed Sci. Res. 9, 209-217.

LIANG YH, SUN WQ (2000) Desiccation tolerance of recalcitrant Theobroma cocoa embryonic radicles: the optimal drying rate and its physiological basis. J. Exp. Bot. 51, 1911-1919.

MATSUMURA H, MIYACHI S (1980) Cycling assay for nicotinamide dinucleotides. Methods Enzymol. 69, 465-470.

McCORD JM, FRIDOVICH I (1969) Superoxide dismutase. An enzymic function for erythrocuprin (hemocuprin). J. Biol. Chem. 224, 6049-6055.

MISHRA NP, MISHRA RK, SINGHAL GS (1993) Changes in the activities of anti-oxidant enzymes during exposure of intact wheat leaves to strong visible light at different temperatures in the presence of protein synthesis inhibitors. Plant Physiol. 102, 903-910.

MISHRA NP, FATMA T, SINGHAL GS (1995) Development of antioxidative defense system of wheat seedlings in response to high light. Physiol. Plant. 95, 77-82.

MURASHIGE T, SKOOG F (1962) A revised medium for rapid growth and bioassay with tobacco tissue cultures. Physiol. Plant. 15, 473-497.

NTULI TM, PAMMENTER NW (2009) Dehydration kinetics of embryonic radicles from desiccation-sensitive seeds: an assessment of descriptive models. J. Integr. Plant Biol. 51, 1002-1007.

NTULI TM, BERJAK P, PAMMENTER NW, SMITH MT (1997) Effects of temperature on the desiccation responses of seeds of Zizania palustris. Seed Sci. Res. 7, 145-160.

NTULI TM, FINCH-SAVAGE WE, BERJAK P, PAMMENTER NW (2011) Increased drying rate lowers the critical water content for survival in embryonic radicles of English oak (Quercus robur L. J. Integr. Plant Biol. $53,270-280$

PAMMENTER NW, BERJAK P (1999) A review of recalcitrant seed physiology in relation to desiccation-tolerance mechanisms. Seed Sci. Res. 9:13-37.

PAMMENTER NW, VERTUCCI CW, BERJAK P (1991) Homeohydrous (recalcitrant) seeds: Dehydration, the state of water and viability characteristics in Landolphia kirkii. Plant Physiol. 96, 1093-1096.

PAMMENTER NW, BERJAK P, FARRANT JM, SMITH MT, ROSS G (1994). Why do stored hydrated recalcitrant seeds die? Seed Sci. Res. 4, 187-191.

PAMMENTER NW, BERJAK P, WALTERS C (1999) The effect of drying rate, and processes leading to viability loss in recalcitrant seeds. In: Marzalina, M, Khoo, KC, Jayanthi, N, Tsan, FY, Krishnapillay, B (eds) IUFRO Seed Symposium 1998: Recalcitrant seeds. Forestry Research Insitute, Kuala Lumpur, Malaysia. pp. 14-24.

PAMMENTER NW, BERJAK P, WESLEY-SMITH J, VANDER WILLIGEN C (2002). Experimental aspects of drying and recovery. In: Black, M. and 
Pritchard, H. (eds) Desiccation and survival in plants: drying without dying. CAB International, Wallingford. pp. 93-110.

PAMMENTER NW, GREGGAINS V, KIOKO JI, WESLEY-SMITH J, BERJAK P, FINCH-SAVAGE WE (1998). Effects of differential drying rates on viability retention of reclacitrant seeds of Ekebergia capensis. Seed Sci. Res. 8,463-471.

PAMMENTER NW, NAIDOO S, BERJAK P (2003) Desiccation rate, desiccation response and damage accumulation: can desiccation sensitivity be quantified? In: Nicolás M, Bradford KJ, Côme D, Pritchard HW, eds. The Biology of Seeds: Recent Research Advances. CABI Publishing, Wallingford. pp. 319-325.

PRITCHARD HW (1991) Water potential and embryonic axis viability in recalcitrant seeds of Quercus rubra. Ann. Bot. 67, 43-49.

ROACH T, BECKETT RP, MINIBAYEVA F, COLVILLE L, WHITAKER C, CHEN H, BAILLY C, KRANNER I (2010) Extracellular superoxide production, viability and redox poise in response to desiccation in recalcitrant Castanea sativa seeds. Plant, Cell Environ. 33, 59-75.

SCHONER S, KRAUSE GH (1990) Protective systems against active oxygen species in spinach: response to cold acclimation in excess light. Planta 180, 383-389.

SIEGEL FGA, BING RJ (1956) Effect of a cardiac glycoside (Cedilanid) on the sodium and potassium balance of the human heart. Circ. Res. 4, 298-301.

SONG SQ, BERJAK P, PAMMENTER N (2005) Desiccation sensitivity of Trichilia dregeana radicles and antioxidant role of ascorbic acid. Acta Bot. Sinica 46, 803-810.
SONG SQ, TIAN MH, KAN J, CHENG HY (2009) The response difference of mitochondria in recalcitrant Antiaris toxicaria radicles and orthodox Zea mays embryos to dehydration injury. J Integr. Plant Biol. 51, 646-653.

SUN WQ (2002) Methods for the study of water relations under desiccation stress. In: Black, M. and Pritchard, H. (eds) Desiccation and survival in plants: drying without dying. CAB International, Wallingford. pp. 47-91.

VERTUCCI CW, FARRANT JM (1995) Acquisition and loss of desiccation tolerance. In: Kigel J, Galili G (eds) Seed development and germination. Marcel Dekker, Inc. New York, Basel, Hong Kong. pp. 237-271.

WALTERS C, FARRANT JM, PAMMENTER NW, BERJAK P (2002) Desiccation stress and damage. In: Black M. and Pritchard H. (eds) Desiccation and survival in plants: drying without dying. CAB International, Wallingford, UK. pp. 263-291.

WALTERS C, PAMMENTER NW, BERJAK P, CRANE J (2001) Desiccation damage, accelerated aging and metabolism in desiccation tolerant and sensitive seeds. Seed Sci. Res. 11, 135-148.

WESLEY-SMITH J, PAMMENTER NW, BERJAK P, WALTERS C (2001) The effects of two drying rates on the desiccation tolerance of embryonic radicles of recalcitrant jackfruit (Artocarpus heterophyllus Lamk.) seeds. Ann. Bot. 88, 653-664.

WEXLER A (1997) Constant humidity solutions. In: Lide, DR (ed) Handbook of chemistry and physics, $78^{\text {th }}$ edition. CRC Press, New York. pp. 24-25.

ZHAO Z, HU X, ROSS CW (1987) Comparison of tissue preparation methods for assay of nicotinamide coenzymes. Plant Physiol. 84, 987-988. 